\title{
The changing face of urban growth:
}

\section{An analysis using earth observation data}

\author{
M. Wurm ${ }^{1}$, H. Taubenböck ${ }^{1}$, T. Esch ${ }^{1}$, S. Fina ${ }^{2} \&$ S. Siedentop ${ }^{2}$ \\ ${ }^{1}$ German Remote Sensing Data Center (DFD), German Aerospace Center (DLR), Oberpfaffenhofen, Germany \\ ${ }^{2}$ Institute of Regional Development Planning (IREUS), University Stuttgart \\ michael.wurm@dlr.de
}

\begin{abstract}
This paper represents research effort to monitor the development of urban morphology using earth observation data. For the city of Cologne in Germany, satellite images over a time period of more than 30 years are analyzed regarding the urban development. These urban footprints describe the 2-D spatial urban extension of the city at a given point in time. These data are spatially intersected with a geometrically highly resolved 3-D building model derived from a digital surface model. The data set allows for a 2-D and 3-D growth analysis of Cologne for more than three decades based on three variables: area, building volume and the number of buildings. The analysis underlines the hypothesis that recent urban growth is much more space consuming than historic urban developments.
\end{abstract}

\section{INTRODUCTION}

Cities are exposed to constant development pressures and changes over time. The velocity and dimension of these urbanization processes vary significantly around the world with respect to cultural, economic, demographic and social processes and backgrounds. While many Asian megacities have sprawled to a multiple of their original size over the last few decades, urban areas in the western world have mostly stabilized in size. Urbanization in Europe took mainly place in the $19^{\text {th }}$ century when cities have increased much of their size due to industrialization. Today, for instance in Germany, the world's third largest economy, almost two third of the population live in urban areas [1]. However, sub-urbanization and re-urbanization processes have not entirely come to an end. In Germany, about 100 hectares of soil is still being converted to built-up area every day [2]. The share of buildings and related open spaces accounts for about $40 \%$ of the newly sealed surfaces. Measuring and quantification of local urban growth is conventionally done using statistical data of cadastral data. Acquisition and actualization of these data however, is very time consuming and costly. A true spatial approach for a detailed measuring of local urbanization can be achieved using the advantages of earth observation data.

Area-wide earth observation data allow for the mapping of entire urban regions. It is possible to visualize and quantify the spatial dimension of urban growth from the data. Especially space-borne earth observation systems have been widely used to detect and measure the spatial dimension of urban areas throughout the world [3, 4]. Spatial urbanization can be mapped since the launch of the first commercial earth observation satellite Landsat in the 1970s. The satellite data allow for a detailed delineation of urban footprints and a consistent monitoring of urbanization processes over time.

Next to the wide availability of high and medium spatially resolved satellite data, developments in remote sensing have also led to a broad access of large-scale 3-D data sets of urban areas. Through the operationalization of airborne LiDARsystems (Light Detection And Ranging) and also photogrammetric approaches, many cities are also mapped in their third dimension. The results allow for an area-wide mapping of urban areas and therefore also for a quantification of the cities' growth in the vertical dimension. The combination of multi-temporal 2-D and 3-D remote sensing data is the basis for an assessment of urban growth both in area and volume. In this context, this paper describes the integration of space-borne and air-borne earth observation data to monitor and quantify urbanization processes at the example of a German city.

\section{STUdy AREA AND DATA SETS}

The scope of the study covers the city of Cologne, one of the largest population hubs in Germany. It is located at the Rhine river in the federal state of North Rhine-Westphalia and is home to about 1 million inhabitants. The administrative area covers about $400 \mathrm{~km}^{2}$. Although Cologne has also played an important role throughout the Middle Ages, most of the urban development took place in the $19^{\text {th }}$ century.

A time series of space-borne earth observation data is used and integrated with high resolution 3-D data from airborne LiDAR to monitor the urban development of Cologne,. The spatial delineation of the urban area is assessed for four points in time: 1975, 1989, 2000 and 2010. The satellite imagery has been acquired by sensors of the Landsat program.

The Landsat program was launched in 1972 as the world's first civil earth observation satellite system. Since then several satellites within the Landsat program have acquired timely continuous data of the Earth's surface. The sensors acquire spectral information in four (MSS) and six (TM) spectral bands, respectively. The spatial resolution of the data varies between $60 \mathrm{~m}$ and $30 \mathrm{~m}$ while covering an area of 185*185 km [5].

The data holding the information on the third dimension of Cologne comes from an active remote sensing system. The 
airborne LiDAR measures the running time of a laser beam between the sensor, the reflecting surface and back. By means of GPS (Global Positioning System) and INS (Inertial Navigation System) the absolute position of the reflecting object - in x, y and z-direction - can be captured [6]. Depending on the density of the laser beams, the geometrical resolution may vary between a few centimeters and a few meters. A very common utilization of the point cloud is the generation of a high resolution DSM (Digital surface model). The DSM represents the elevation of the Earth's surface including all objects above the surface like buildings or high vegetation. The results can be used for the delineation of individual building footprints and hence the generation of 3-D city model [7, 8, 9]. The specifications of the data sets used for this study are summarized in Table I.

Figure 1 shows a visual representation of the remote sensing data sets. It covers the administrative boundaries of Cologne and the different data sources: a) represents the Landsat TM image (from the year 2003), b) shows the normalized digital surface model (nDSM). In an nDSM the height values are normalized using height information from a digital elevation model (DEM) so that only elements above the Earth's surface are represented in the data set (e.g. buildings). However, alongside buildings, high elevations are represented in the nDSM as well. Before the extraction of the buildings, vegetation is excluded based on spectral information in high resolution satellite data. A coverage of RapidEye data is used to derive a vegetation mask based on the normalized difference vegetation index (NDVI) to exclude these areas from the building segmentation (cp. III).

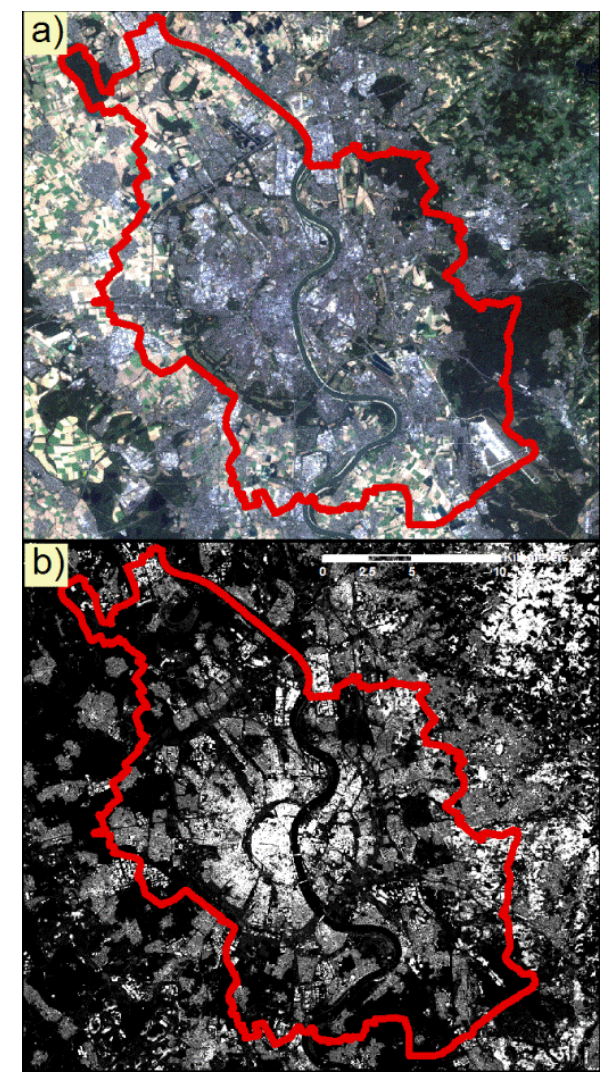

Figure 1. Remote sensing data sets.
TABLE I. Remote SENSING DATA Sets

\begin{tabular}{|l|l|l|l|l|l|}
\hline \multicolumn{4}{|l|}{ Data specifications } \\
\hline $\begin{array}{l}\text { Acquisition } \\
\text { year }\end{array}$ & 1975 & 1989 & 2000 & 2010 & $2007 / 2009$ \\
\hline $\begin{array}{l}\text { Data } \\
\text { source }\end{array}$ & $\begin{array}{l}\text { Landsat } \\
\text { MSS }\end{array}$ & $\begin{array}{l}\text { Landsat } \\
\text { TM }\end{array}$ & $\begin{array}{l}\text { Landsat } \\
\text { TM }\end{array}$ & $\begin{array}{l}\text { Landsat } \\
\text { TM }\end{array}$ & $\begin{array}{l}\text { LiDAR/ } \\
\text { RapidEye }\end{array}$ \\
\hline Data type & $\begin{array}{l}4 \\
\text { spectral } \\
\text { bands }\end{array}$ & $\begin{array}{l}6 \\
\text { spectral } \\
\text { bands }\end{array}$ & $\begin{array}{l}6 \\
\text { spectral } \\
\text { bands }\end{array}$ & $\begin{array}{l}\text { 6 spectral } \\
\text { bands }\end{array}$ & elevation \\
\hline Utilization & $\begin{array}{l}\text { 2-D } \\
\text { growth }\end{array}$ & $\begin{array}{l}\text { 2-D } \\
\text { growth }\end{array}$ & $\begin{array}{l}\text { 2-D } \\
\text { growth }\end{array}$ & $\begin{array}{l}\text { 2-D } \\
\text { growth }\end{array}$ & $\begin{array}{l}\text { Building } \\
\text { volume }\end{array}$ \\
\hline
\end{tabular}

\section{IMAGE CLASSIFICATION}

This chapter describes the strategy and the methods for data interpretation. The remote sensing data sets initially only represent data, not information. Hence, image information has to be turned into classified spatial geographic information before urban growth can be analyzed.

\section{A. Image interpretation}

The remote sensing images are used to extract and delineate the urban areas and to assess the spatial urban growth of Cologne over time. Due to the fact that data from two different earth observation systems are interpreted, the image interpretation strategies vary with respect to the data.

The image interpretation of the spectral information for the four points in time (Landsat) follows a straight-forward image classification strategy. The urban area of Cologne is classified by identifying impervious surfaces in the spectral data sets using automatic image classification methods. An object-based image interpretation method helps to classify the extent of the urban area for each year. This method focuses not on the individual pixel information in the raster images but on groups of spectrally similar pixels. In this context, the images are subdivided into homogenous groups of pixels first. They can then be identified as objects using a multi-resolution image segmentation approach [10]. The subsequent image classification is then based on the image objects. The application of object-based image classification allows for an image classification based not only on spectral but also on semantic features. Furthermore, the outcome of the classification process shows a more natural representation of the urban footprint compared to a pixel-wise classification. Each of the Landsat-scenes was classified using this objectbased approach. The features for the classification are based on NDVI, which is sensitive to active vegetation. Hence, it allows for the distinction of impervious surface as well.

The image interpretation of the height information for the 3-D building detection is based on the nDSM. As the data contains only elevated features above the ground surface and no topographic information, buildings and high vegetation can be detected according to their relative elevation. The classification strategy is also based on an object-based approach where individual buildings are segmented based on their elevation values. The method follows a local contrast split segmentation that results in individually delineated building footprints and a height value for each building [11]. Based on 
the results, the area and the volume of each building can be quantified in terms of a 3-D building model.

\section{B. Classified Urban Footprints 1975-2010}

The results of the image classification for the four satellite images and the 3-D building model are displayed in Figure 2. It shows the spatial extensions of the urbanized areas for each point in time. The dark green color represents the impervious surfaces for the year 1975, the light green color indicates the urban growth between 1975 and 1989, the following eleven years are represented in yellow, and the last ten years in red. Based on these masks it is possible to quantify the urbanization processes spatially. The value of this approach is that, through the integration of the 3-D building model, it is now possible to estimate the three-dimensional urbanization for a time period of 35 years.

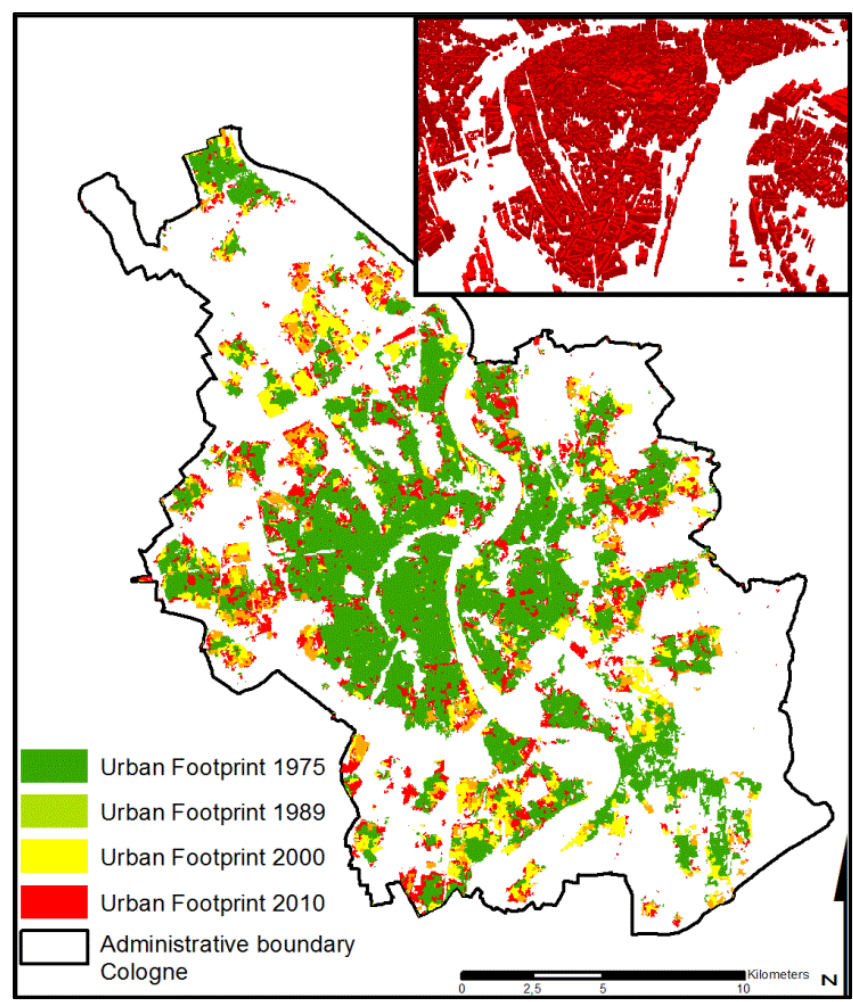

Figure 2. Urban footprints 1975-2009 and 3-D building model.

\section{Accuracies of Image Classifications}

Automatic classification of thematic and spatial information from remote sensing imagery comes up with the advantage of being a fast and efficient tool for information extraction. Additionally, methods can be transferred on other data sets. However, each remote sensing data set represents an individual data set with individual characteristics. Hence, image classification results do not represent exactly reality and comprises classification errors.

For the assessment of the thematic accuracy of the areal growth and the 3-D city model, results have been compared to reference data and analyzed. The reference for the areal assessment of urban growth is taken from the area-wide landcover/land-use classification CORINE landcover [12]. The entire area of the classification products was compared and quantified in an error matrix. Total accuracies and kappa coefficients [13] are presented in Table II.

TABLE II. ACCURACIES OF AREAL GROWTH

\begin{tabular}{|c|c|c|c|c|}
\hline Year & $\mathbf{1 9 7 5}$ & $\mathbf{1 9 8 9}$ & $\mathbf{2 0 0 0}$ & $\mathbf{2 0 1 0}$ \\
\hline $\begin{array}{c}\text { Total } \\
\text { accuracy }\end{array}$ & $90.70 \%$ & $91.27 \%$ & $90.91 \%$ & $90.91 \%$ \\
\hline Kappa & 0.73 & 0.74 & 0.74 & 0.75 \\
\hline
\end{tabular}

Next to the accuracy of the areal growth, also the accuracy of the 3-D building model was assessed. Reference data was taken from the official building cadaster of Cologne and areal accuracy as well as the accuracy in the third dimension was assessed. Results can be viewed in Table III.

TABLE III. ACCURACIES OF 3-D BUILDING MODEL

\begin{tabular}{|c|c|c|c|c|}
\hline & $\begin{array}{c}\text { Total } \\
\text { accuracy }\end{array}$ & Kappa & $\mathbf{R}^{2}$ & $\boldsymbol{\sigma}$ \\
\hline Area & $97.43 \%$ & 0.76 & - & - \\
\hline Height & - & - & 0.81 & 3.76 \\
\hline
\end{tabular}

\section{ANALYSIS OF URBAN GROWTH 1975-2010}

The resulting geo-information products open up a number of analysis options for urban growth processes: A) Areal growth with respect to location B) 3-dimensional growth $\mathrm{C}$ ) Interpretation.

\section{A. Areal growth with respect to location}

The total urbanized area for the year 1975 represents about $61 \%$ of the total urbanized area for the year 2009. The city therefore grew over a third of its original size in that time span. In detail, growth rates vary from $14 \%$ between 1975 and 1989, declining to $7.5 \%$ in the 1990 s and rising again to $17 \%$ in the 2000s. As displayed in Figure 2, the urbanized area for the year 1975 is mainly located around the historic center of the city. The urban developments after this year took place at the edge of the center towards peri-urban land. Next to newly developed areas in the decades afterwards, densification of the existing inner city took place.

\section{B. 3-dimensional growth}

For the change analysis of the building volume only data for the year 2009 was available. Hence, analysis of the 3-D growth over the entire time period is based on the simplifying assumption that the extracted buildings in 2009 have not been modified in the previous time periods.

Hence, the change in building volume is calculated as the following: the building volume for the year 2009 represents $100 \%$ and the spatial overlay of the building model and the urban footprints of the previous years from Landsat data represent the urban and building growth for this time period.

In this respect, the measured increase in building volume for the entire period is higher than the areal growth. The year 1975 represents already $72.6 \%$ of the total building volume calculated for 2009. The growth rates for the following years 
show an increase of almost $11 \%$ between the years 1975 and $1989,16.5 \%$ in the 1990 s and $27.4 \%$ in the 2000 s.

\section{Interpretation}

The main result of this study is that the areal expansion of suburban Cologne is higher than the growth in volume. This is a good indication for the fact that urban growth became more space consuming over time. It confirms that less dense urbanization or splinter development dominated urban development over the last decades. Before the 1970s the builtup areas in suburban Cologne have been compact and dense, the density of newly developed areas is significantly lower. The same observation also applies to the number of buildings: in $197564.3 \%$ of all buildings make up for $72.6 \%$ of the volume. In balance this means that only $27.4 \%$ of the volume is used by the additional $35.7 \%$ of all buildings developed since then.

A visualization of the 2-D and the 3-D relative growth for all four points in time is displayed in Figure 3. It displays the relative growth of the indicators of urban growth for the four points in time.

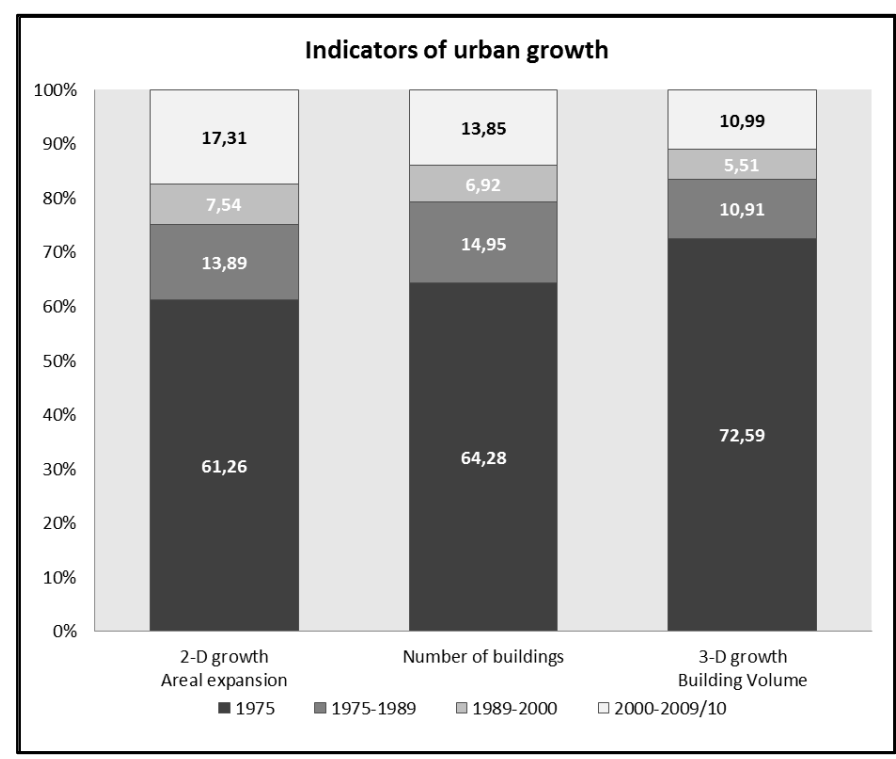

Figure 3. 2-D and 3-D indicators of urban growth for Cologne between 1975 and 2009.

\section{DISCUSSION AND OUTLOOK}

This study illustrates the analytical capabilities of 2-D and 3-D remote sensing data for the purpose of monitoring urban growth and urban form in Germany. Through the combination of different remote sensing products it is now possible to measure urban expansion not only in terms of areal size, but also in terms of building volume. A first application of this novel approach shows that newly developed urban areas in Cologne have significantly lower densities than inner city areas like the historic city center. Since the data is available on the building level, the results can be output for any district or suburb. By doing so, disaggregated information on 3-D building densities is now available to planning practitioners through relatively straight forward and cost-effective data generation methods. In combination with additional information (i.e. population, migration, land use, employment, etc.) this data will help to develop new and highly valuable indicators on urban development. As illustrated here, indicators can be calculated for a time period of more than 30 years, depending on Landsat image availability. The current study represents a case study for one of the largest cities in Germany. Future studies will allow comparative studies for other city regions to be conducted based on this methodology as well.

\section{ACKNOWLEDGMENT}

The authors would like to thank the German Research Council (DFG) for funding the research project "Polyzentralität deutscher Stadtregionen”; Sponsorship Code: TA 800/1-1 \& SI 932/4-1. Beyond this, we thank Ute Meurer from Bezirksregierung Köln for the provision of the laserscan data (C)Geobasis NRW 2011 and Udo Lapschies from Umwelt- und Verbraucherschutzamt der Stadt Köln for providing reference data. And we also thank the RapidEye science team for providing RapidEye data within the project "609 Polyzentralität deutscher Stadtregionen”.

\section{REFERENCES}

[1] United Nations, Department of Economic and Social Affairs, Population Division: World Urbanization Prospects, the 2011 Revision. New York, 2012.

[2] Federal Ministry of Education and Research: Paths to Sustainable Land Management - Topics and Projects in the REFINA Research Programme, http://edoc.difu.de/edoc.php?id=QPUFXL6Y, 26 p., 2008.

[3] Taubenböck H, Esch T, Felbier A., Wiesner M, Roth A and Dech S: Monitoring of mega cities from space. In: Remote Sensing of Environment, vol. 117, pp. 162-176, 2012

[4] Esch, T., Thiel, M., Schenk, A., Roth, A., Müller, A. and Dech, S.: Delineation of Urban Footprints From TerraSAR-X Data by Analyzing Speckle Characteristics and Intensity Information, IEEE Transactions on Geoscience and Remote Sensing, Vol. 48, Issue 2, pp. 905-916, 2010.

[5] Lillesand, T.M., Kiefer, R.W. and Chipman, J.W.: Remote Sensing and Image Interpretation, John Wiley \&Sons, 704 p., 2003.

[6] Hofmann, A.D.: An approach to 3D building model reconstruction from airborne laser scanning data using parameter space analysis and fusion of primitives,” unpublished PhD thesis, Dresden, 115 p, 2005.

[7] Weidner, U.: Building extraction from digital elevation models, Technical report, 56 p., 1995.

[8] Haithcoat, T., Song, W., Hipple, J.: Automated building extraction and reconstruction from LiDAR data, ICREST, Project report, 27 p., 2001.

[9] Rottensteiner, F., Trinder, J., Clode, S., Kubik, K., Lovell, B.: Building detection by Dempster-Shafer fusion of LiDAR data and multispectral aerial imagery, ICPR'04, 4 p., 2004.

[10] Baatz, M. und Schäpe, A. (2000) 'Multiresolution segmentation - an optimization approach for high quality multi-scale image segmentation', In: Strobl, J., Blaschke, T. und Griesebner, G. (eds.) Angewandte Geographische Informationsverarbeitung XII. Beiträge zum AGITSymposium, Salzburg (05.-07. Juli), pp. 12-23, 2000.

[11] Wurm, M., Taubenböck, H., Schardt, M., Esch, T. and Dech, S.: Objectbased image information fusion using multisensor earth observation data over urban areas, International Journal of Image and Data Fusion, Vol. 2, p. 121-147, 2011.

[12] Keil, M., Kiefl, R., Strunz, G.: CORINE Land Cover 2000 - Germany. Final Report, http://www.corine.dfd.dlr.de/media/download/clc2000 finalreport de.pdf

[13] Congalton, R.G., Green, K.: Assessing the accuracy of remotely sensed data: principles and practices, Boca Raton, FL: CRC Press, 183 p. 